\title{
Research on the Building Drainage Water Supply System Design Methodology based on the New Design Standard
}

\author{
Xiaofeng Wang ${ }^{1}$ \\ ${ }^{1}$ College of Civil Engineering And Urban Construction, Jiujiang University, \\ Jiujiang,Jiangxi, 332005 China
}

\begin{abstract}
In this paper, we conduct theoretical research on the building drainage water supply system design methodology based on the new design standard. According to the structure of engineering construction standard system in our country can be divided into basic, universal and special structure of three layers. General guide water supply and drainage engineering structure design standards for the specialty of the standard type. Building water supply and drainage design standards is the main basis. Our research will enhance the overall performance of the system which will be meaningful.
\end{abstract}

Keywords: Drainage Water Supply System; New Design Standard; Systematic Description.

\section{Introduction}

In the process of modern urban construction, water supply and drainage engineering in the construction of the whole project and construction process plays a very important role. In recent years, water supply and drainage engineering design in improving the standardization of the standard degree, on the one hand provide a good reference for practical engineering structure design, on the other hand also laid a good preparation for the construction of standardization. In the same specification also highlights a series of problems in the course of execution. In every process needs related staff strictly according to the engineering construction standards, their work, to ensure the overall quality of building water supply and drainage engineering, higher social and economic benefits. According to the structure of engineering construction standard system in our country can be divided into basic, universal and special structure of three layers. Before two standards is mainly composed of the relevant administrative units issued and implemented, special standard is different from the foundation and universal standard, it has its certain scope and technical objects, most of the special standard content all by our country's engineering construction standards association to organize the planning and design, belongs to the category of the recommended standard, and has strong pertinence, has its objective guiding value, basically to engineering design quality and the investment benefit of the whole project. Although such specific standard does not have legal effect, but its list of project bidding documents, can the restraint of contract law, and have its enforcement effect. General guide water supply and drainage engineering structure design standards for the specialty of the standard type. Building water supply and drainage design standards is the main basis, the designers to design production and reasonable application of the existing building water supply and drainage design standards, is the designer to design the premise that conform to the requirements of the construction quality of the product which is the key to the system standard.

Building water supply and drainage engineering is facing opportunities and challenges which are summarized as the following parts. (1) The change of the building water supply and drainage industry status. With the rapid development of our national economy, the construction industry in our country also ushered in the rapid development, which also in a certain extent, promotes the development of 
building water supply and drainage engineering, which makes an increasing number of our country building water supply and drainage system, which also marks the Chinese building water supply and drainage engineering is becoming more and more complex, the workload than ever also has greatly improved, which requires engaged in building water supply and drainage in the majority of workers with high professional quality and work experience which is able to timely handling of building water supply and drainage engineering. (2) As accelerating socialist modernization construction in China, also in order to meet the demand of people's production and life, countries in the tightening of relevant construction engineering quality supervision at the same time, also improve in building engineering construction standards, and through legislative means for integrated management of the construction projects nationwide. For the water supply and drainage engineering construction project which also puts forward a new design and construction standards. (3) Through the analysis of construction industry in our country the actual development needs, to design scientific, rationalization of building water supply and drainage system application is necessary. (4) To do a good job in building water supply and drainage design requires the coordination of the design phase. To do a good job of health technology design science, for example, for building water supply and drainage system is perfect which need to make sure that each of the construction workers to master basic skills.

In this paper, we conduct theoretical research on the building drainage water supply system design methodology based on the new design standard. In the process of building water supply and drainage system design, building water supply and drainage design standard of control is necessary, which requires for building water supply and drainage design of common problems were analyzed, and the implementation of the related work of building water supply and drainage design, so as to realize the sound of building water supply and drainage design system, through its internal coordination of each part, is more advantageous to the present stage of building water supply and drainage work efficiency improvement. In the next paragraphs, we will discuss the issues in detail with analysis.

\section{Our Proposed Methodology}

The Drainage Water Supply System. Water supply and drainage engineering structures contained in the content is relatively complex, not only cover the content in aspects of piping material, also engaged in water treatment, water component architecture design knowledge. General water supply and drainage engineering structure mainly shell composite structures, plate combined with plate and shell combination is given priority to, belong to the special structure design of the content. The building design and construction applications, the need to be carried out in accordance with the relevant laws and regulations formulated by the state building water supply and drainage construction design. Follow the principle of taking the user as the main service object. It requires user's own interests, to ensure water supply and drainage design work.

The change of the water supply and drainage engineering structure of the main bearing load under pressure to water qualitative change, engineering components on both ends of the temperature and humidity changes, the influence of the seasonal aspect and so on, is not the same as the traditional civil building structure design. At the same time, building environment and the change of the structure size, and other external factors, the difference of the structure can also lead to water and wastewater engineering. In order to ensure the overall benefits of high-rise buildings, the design of building fire system is necessary and it needs to be carried out in accordance with the building water supply and drainage design code in China, to a certain type 
of the application of drain, better to control the fire.

In the process of the application of plastic drain pipe, according to the plastic material, need to be control of pipe diameter. Therefore, the engineering structure design needs to have its more targeted design reference standard. Since most of the current water supply and drainage engineering structure design of pipe diameter are bigger, so you must pay attention to the bearing capacity calculation, in strict accordance with the foundation, the specialty standard implementation, to avoid confused with civil construction structure design standard. In the design of building water supply and drainage, it is necessary to good for pipeline layout. This needs according to the standard of design standard, the determination of the position of water supply and drainage pipeline construction projects, to normative operation, ensures good line spacing, avoid appearing too big or too small. Settings in some water supply and drainage, the problems of ordinary plastic pipes is also more, because of its thin wall, water running, also can produce a series of cavitation, lead to the resonance between the noise and its water which unfavorable to around the user's normal rest. In water supply and drainage engineering structure design, guarantee the durability of structures is important to note in the design of the problem. General factors influencing the durability of structures including objective environmental factors and other external factors, including the engineering environment, location, water and soil contact frequently, etc. Due to environmental conditions belongs to uncontrollable factors, and thus generally in such aspects as material, section, the structure design of relevant treatment measures. The detailed method will be discussed later.

The New Design Standard and the Applications. Building water supply and drainage design standards mainly have three kinds, namely, basic standards, common standards and professional standards. Common standards for a standardized object the common standards for a larger coverage and it is usually a special standard for reference. Building water supply and drainage design in our country is more common standards. Special standard standardization is a pointer to a particular object or supplement common standards, extension of the standards set and its coverage is not big. The meaning of water supply and drainage system and its design standards exist the problem of building water supply system is a mass in certain combinations by water, water, water distribution and water treatment facilities. Refers to the network through the pipeline and some auxiliary facilities, according to the user's production, life requires organized transportation to the destination of the water. The main task of the power plant water supply system is to ensure continuous boiler water supply, which is mainly composed of water pumps, water supply pipes and valves.

Drainage system is the collection of drainage, transportation, water quality and other equipment according to the combination of the whole of the integrated. Building water supply and drainage design standards promulgated by the state according to different regulations and application range have different wording, such doing can facilitate professionals treat when executive standard, to strengthen and improve the design and ensure safety in production. In recent years, with the construction industry in our country's emphasis on water supply and drainage design standards, past the old specification has been unable to adapt to the requirement of the modernization, as a result, the new policy is imperative. In the face of new phase, design personnel should update ideas, grasp the dynamics of the standard direction, according to the new standard and the content change, timely adjust, guarantee applies to new design concept, improve the engineering design of products, in addition, but also pay attention to the implementation of the new standard time, once the design products with the new rule conflict, to look at the time of concrete as the 
case may be, the design of time after the new regulations issued, it must be strictly according to the new standard.

The Design Standard of China and the Abroad. In recent years, the rapid development of China's economy to foreign architectural design provides a platform for far greater than their own country, they focus on large projects tenders in our country. We can say that they pressed Chinese architects have to out of breath, domestic building design source was helpless. Because our country must after the foreign design companies won the bid and Chinese class the design unit cooperation, we have the opportunity of cooperation with foreign counterparts and experiences. We in cooperation with foreign design companies some more complex projects, some of their basic design cannot possess guiding significance, in order to ensure a high quality design, even if sometimes foreign design company to do preliminary design, the Chinese side to do construction drawing, we also often their overall design again first, and then communicate with them. Facts have proven that this approach is effective. Foreign design strengths embodied in their manufacturing technology and enterprises which will affect our usually and enables us to enhance their enterprises and their products.

The Proposed Novel Design Methodology. Before the building water supply and drainage engineering design, designers must first clear the scope of design task and design. Changing the type of building water supply and drainage engineering design, the design site terrain temperature difference is very big, the requirements of the project owner is endless also and same, so do engineering for a comprehensive understanding is the first step to be designed. Because it is directly related to design, it is also the most crucial step. From the point of view of plane, in order to prevent a variety of design of pipeline crossing or rushed to take the optimal position, must, in accordance with the relevant specification requirements to determine various pipeline horizontal position, this also is helpful for pipeline after put into use and convenient maintenance and expansion, at the same time, the line also should be in the process of building a variety of pipeline, in turn, determine the height from the top down, so that village drain height and the area of municipal drainage pipeline connection and maintenance. In addition, if the residential area of relatively flat topography, that may arise in the process of pipeline construction, a certain degree of deviation to ensure the accuracy of the pipeline construction, must be appropriate to expand the dirt, rain water pipe diameter and grade, so that we can make the sewage and rainwater more quickly into the zone of the city.

In general, the design of water supply should be determined according to different types of water, so as to guarantee accuracy: for comprehensive water, should according to the residents living water quota and the highest daily variation coefficient of comprehensive determination and analysis, to determine the size of the water supply. For industrial water, the water supply should be according to the size of the staff and production need to how much analysis and calculation. For fire water, the water and the determination of water pressure size should be in accordance with the relevant provisions and the actual situation analysis and calculation. Therefore, we propose our suggestions to modify the current design pattern. (1) On the overall design of the building, floor drain design optimization is necessary, so as to avoid return flavor of floor drain. This should also be in accordance with the work of building water supply and drainage design code in China, to ensure that the floor drain water depth control, to prevent dry function application of floor drain which will avoid the application of some traditional floor drain design. (2) Live in a more common civil residence, water supply and drainage design is need to attach importance to the problems. The situation is the common problem of floor drain drainage device is not reasonable. This needs according to the actual situation of water supply and drainage design, to 
the satisfaction of user needs, for the design of floor drain device. (3) In accordance with the related construction of our country water supply and drainage design specifications, carries on the design of water supply and drainage pipe spacing. Guarantee the life service pipe buried within buildings, guarantee the embedded net drain between parallel spacing. We need to make sure that the drain in the feed pipe below Settings. Feed pipe design and avoid the internal installation of the structure of the building, the need for the adoption of the normalization of civil shuttering. (4) In building energy analysis, can undertake solar energy environmental protection system, also can undertake the application of water-saving sanitary ware, water control. In the pool of wash one's hands and washing basin can be the use of inflatable water mouth that can reduce water consumption control, also can undertake wall pipes material application, to ensure that the head of water loss control. We believe that through the modification, the function will be enhanced.

\section{Conclusion}

In this paper, we conduct theoretical research on the building drainage water supply system design methodology based on the new design standard. Since the reform and opening, with the vigorous development of the construction industry, building water supply and drainage professional also rapid development, has evolved from the original simple houses sanitation design is a relatively complete system of professional. Our method combines the latest design standard to optimize the traditional design method which will not only enhance the performance of the system, but also provide the designers with better guide while designing which has specific meaning.

\section{References}

[1] Fei G. The Characteristics of High-rise Building Water Supply and Drainage and the Features of Water Supply System Design[J]. Urbanism \& Architecture, 2013.

[2] Wang H, Wang J. AutoCAD application in building water supply and drainage system diagram design skills[J]. Network Security Technology \& Application, 2014.

[3] Shao L G, Chen J J, You X J. Design of Water Supply and Drainage,Fire Protection System for Ultra-High-Rise Building of Complex in Zhong Lian Hua Building[J]. Construction \& Design for Project, 2012. 